\title{
Clinical Trial Site Selection Documentation
}

National Cancer Institute

\section{Source}

National Cancer Institute. Clinical Trial Site Selection Documentation. NCI Thesaurus.

Code C115672.

Records detailing both the selection process of a clinical trial site, and the description of the chosen site. 